\title{
ALTERNATIVAS AOS ANTIBIOTICOS PARA EQUILIBRAR A MICROBIOTA GASTROINTESTINAL DE FRANGOS
}

\author{
Larissa Pickler ${ }^{1}$, Elizabeth Santin ${ }^{1}$, Ana Vitória Fischer da Silva ${ }^{1}$ \\ 1 Universidade Federal do Paraná \\ Endereço para correspondência: Larissa Pickler: larissapickler@yahoo.com.br
}

\begin{abstract}
RESUMO: Uma série de aditivos alimentares, incluindo antibióticos, tem sido amplamente utilizados na indústria avícola durante vários anos. A manipulação das funções gastrointestinais e da microbiota dos frangos de corte com aditivos alimentares é reconhecida como uma importante ferramenta para melhorar o desempenho e a eficiência alimentar. Recentemente, as preocupações com os possíveis resíduos de antibióticos e resistência a doenças tem despertado restrições ao uso de antibióticos na indústria animal. A proibição do uso de antibióticos como aditivos na alimentação animal pela União Européia, tem acelerado as investigações sobre aditivos alternativos. Como alternativas, os óleos essenciais e ácidos orgânicos são utilizados na alimentação de frangos de corte para melhorar o desempenho e para controlar a população de microorganismos patogênicos no intestino em sistemas de manejo intensivo. O objetivo desta revisão é abordar a importância do equilíbrio da microbiota intestinal e como ácidos orgânicos e os óleos essenciais podem atuar no desenvolvimento da microbiota intestinal, no controle de bactérias patogênicas e no desempenho zootécnico dos frangos de corte.
\end{abstract}

Palavras-chave: ácidos orgânicos; controle microbiológico; desempenho zootécnico; morfologia intestinal; óleos essenciais.

\section{ALTERNATIVES TO ANTIBIOTICS TO BALANCE THE GUT MICROFLORA IN BROILERS}

\begin{abstract}
A number of feed additives including antibiotics have been widely used in the poultry industry for several years. The manipulation of gut functions and microflora of broiler chickens with feed additives has been recognized as an important tool for improving growth performance and feed efficiency. Recently, the concerns about possible antibiotic residues and disease resistance have aroused great caution in the use of antibiotics in the animal industry. The ban on the use of antibiotics as feed additives for the European Union has accelerated and led to investigations of alternative feed. As alternatives, essential oils and organic acids are already used as feed supplements in broiler chickens to improve growth performance and to control the patogen population in gut under intensive management systems. The aim of this review is discuss about the importance of the balance of intestinal microflora and how organic acid and essential oils could interfere on development of intestinal microflora and in control of pathogenic bacteria and animal performance in broiler chickens.
\end{abstract}

Key Words: organic acids; essential oils; microbiological control; performance intestinal morphology 


\section{INTRODUÇÃO}

Desde a década de 50 os antibióticos são utilizados como promotores de crescimento, controlando microorganismos prejudiciais ao processo de digestão e de absorção e promovendo melhoras nos índices zootécnicos em animais criados sob condições cada vez mais intensivas (Menten, 2001). Em 1997, a Organização Mundial da Saúde (OMS) publicou um relatório sugerindo a ligação entre os antibióticos usados na alimentação dos animais e o aumento da resistência antimicrobiana no homem (World Health Organization, 1997). Em 2000 , outro relatório recomendava que fosse banido o uso dos antibióticos promotores de crescimento de mesma classe dos usados em seres humanos (World Health Organization, 2000). Sendo assim, a partir de janeiro de 2006, a União Européia proibiu o uso de qualquer tipo de antibiótico e quimioterápico como promotor de crescimento na produção animal, que eram vistos como fatores de risco para a saúde pública pelo seu eventual papel na ocorrência de resistência microbiana. As principais alternativas que têm sido pesquisadas incluem prebióticos, probióticos, enzimas, ácidos orgânicos e extratos vegetais (Miltenburg, 2000; Jeauround et al., 2002).

Nurmi e Rantala (1973) foram os primeiros autores a afirmar que a microbiota do trato gastrointestinal beneficia 0 animal hospedeiro com proteção prevenindo a colonização de bactérias patogênicas por meio de exclusão competitiva. Outro benefício é - desenvolvimento de defesas intestinais como o muco, a camada epitelial e a lâmina própria (Tellez et al., 2006). Além da produção de ácidos graxos de cadeia curta, vitaminas e aminoácidos (Tellez et al., 2006). Os ácidos graxos de cadeia curta fornecem energia e auxiliam $o$ controle de microorganismos não desejados, estimulam a proliferação de células epiteliais e o tamanho das vilosidades aumentando a superfície de absorção (Hart et al., 2002; Dibner e Richards, 2005).

O principal desafio da produção avícola hoje se refere à busca de um equilíbrio entre a microbiota e o hospedeiro. Esse equilíbrio baseia-se na presença de microorganismos benéficos ao animal e que não façam competição com o hospedeiro por nutrientes ou estejam envolvidos em toxiinfecção em seres humanos. Nessa linha, alguns princípios ativos podem auxiliar neste controle como é o caso dos ácidos orgânicos e óleos essenciais. Frente a isso, o objetivo desta revisão é abordar a importância da microbiota intestinal e como ácidos orgânicos e óleos essenciais podem atuar no desenvolvimento da microbiota intestinal, no controle de bactérias patogênicas e no desempenho zootécnico dos animais.

\section{DESENVOLVIMENTO}

\section{Microbiota intestinal}

A microbiota intestinal das aves é composta de inúmeras espécies de bactérias, formando um sistema complexo e dinâmico responsável por influenciar fatores microbiológicos, imunológicos, fisiológicos e bioquímicos no hospedeiro (Tannock, 1998).

O número e a composição dos microorganismos variam consideravelmente ao longo do trato gastrointestinal (TGI). A população bacteriana no TGI pode ser influenciada por vários fatores como composição da dieta (MacLean et al., 2004; Santos et al., 2007), idade (Amit-Romath et al., 2004), administração de medicamentos (Alp et al., 1999; Knarreborg et al., 2002; Dumonceaux et al., 2006), ambiente (Torok et al., 2009) e infecções com 
microorganismos patogênicos (Kimura et al., 1976). Além disso, somente cerca de $10-60 \%$ das bactérias existentes no TGI podem ser cultivadas pelos usuais métodos em laboratório, tornando difícil a caracterização bioquímica e genética da microbiota (Zhu et al., 2002). Recentemente, o desenvolvimento de técnicas moleculares (como por exemplo, Reação em Cadeia da Polimerase - PCR) começaram a ser utilizadas tornando possível a descoberta de outras espécies que participam da microbiota no TGI (Nava et al., 2009).

Amit-Romath et al., (2004) avaliaram a composição da microbiota intestinal de frangos de corte em diferentes idades. Aos 4 dias de idade, no ceco, bactérias como $E$. coli e Clostridium sp. constituem cerca de um terço da microbiota, $25 \%$ de Lactobacillus sp., $40 \%$ de Salmonella sp., $2 \%$ de Campylobacter sp. e bactérias do gênero Bifidobacterium sp. não foram detectadas. Aos 14 dias as proporções de Lactobacillus $\mathrm{sp}$. e Bifidobacterium sp. chegam a $40 \%$ e ocorre redução de Salmonella sp. para $10 \%$, as quantidades de E. coli, Clostridium sp. e Campylobacter sp. não sofreram grandes alterações. Aos 25 dias de idade quase a metade das bactérias presentes no ceco eram compostas por Lactobacillus sp. e Bifidobacterium sp., $20 \%$ por Salmonella sp., aproximadamente $30 \%$ de Clostridium sp. e E. coli e pequena quantidade de Campylobacter sp., demonstrando que a idade pode modificar a composição da microbiota intestinal de frangos.

$\mathrm{Na}$ tabela 1 observamos os principais microorganismos encontrados no trato gastrointestinal das aves pela técnica de PCR.
Tabela 1 - Distribuição da microbiota bacteriana no trato gastrointestinal de frangos.

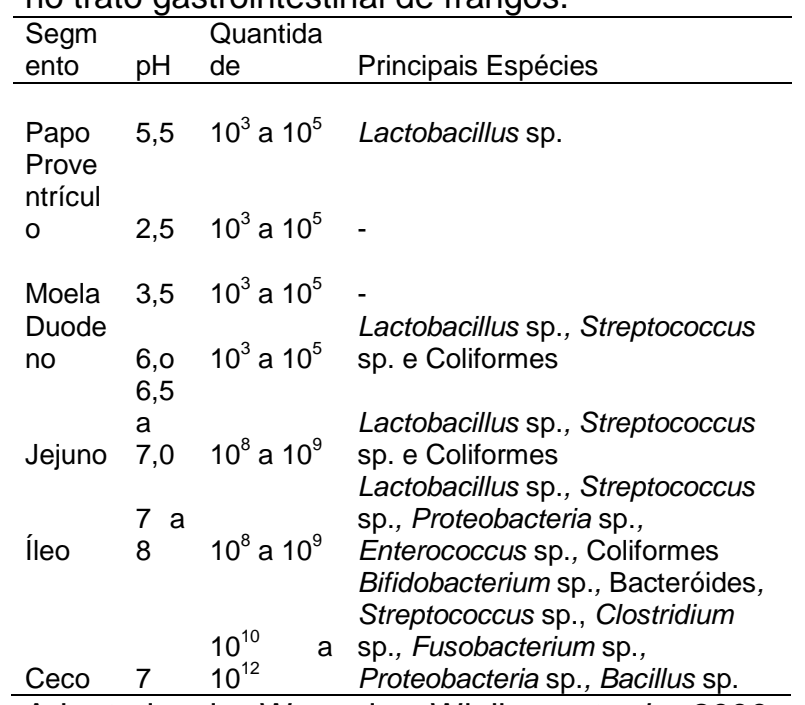

Adaptado de Wan der Wielien et al., 2000; Jiangrang et al., 2003; Amit-Romath et al., (2004).

No papo ou inglúvio existe a predominância de Lactobacillus sp., que produzindo ácido lático e acético impedem 0 crescimento de outras bactérias (Amit-Romath et al., 2004). Nas aves, bactérias patogênicas como Salmonella sp., tem o inglúvio como porta de acesso ao TGl, assim um controle neste local é muito importante para impedir ou diminuir a proliferação de patógenos no TGI. De acordo com Hinton et al. (2000), uma solução de glicose a $7,5 \%$ na água de frangos, pode aumentar a população de Lactobacillus sp. e reduzir $\mathrm{o} p \mathrm{pH}$ no inglúvio levando a redução na contagem de Salmonella sp. e de Enterobactérias.

No proventrículo e moela o $\mathrm{pH}$ é extremamente baixo e poucas bactérias são capazes de tolerar este ambiente, como por exemplo Lactobacillus sp. No duodeno, o pH é próximo ao neutro e os principais microorganismos que colonizam este segmento do intestino delgado, bem como o jejuno e íleo são Lactobacillus sp., Enterococcus sp., Streptococcus sp. e Coliformes (Wan der Wielien et al., 2000), no íleo também foi encontrado a presença de Proteobacteria sp. (Jiangrang et al., 2003). O ceco é reconhecido como o 
segmento de maior colonização de microorganismos e é onde ocorre a fermentação microbiana, sendo que grande número de bactérias grampositivas e gram-negativas estão presentes neste local como Bifidobacterium sp., Bacteróides, Streptococcus sp., Clostridium sp., Eubacterium sp., Lactobacillus sp., (Wan der Wielien et al, 2000) Fusobacterium sp., Proteobacteria sp. e Bacillus sp. (Jiangrang et al, 2003).

Estes diferentes microorganismos convivem em constante processo de exclusão competitiva que pode ser definido como a inabilidade de uma população de microrganismos em estabelecer-se no intestino, em razão da presença de outra população bacteriana (Nurmi e Rantala, 1973). Além dessa competição entre os microorganismos, o estabelecimento da microbiota é influenciado pela inclusão/exclusão imunológica, que se refere à interação entre os microorganismos e o hospedeiro. A inclusão/exclusão imunológica está relacionada com a produção de Imunoglobulina A $(\lg A)$ pelo hospedeiro que facilita ou dificulta a adesão de bactérias na mucosa intestinal. Quando o microrganismo é benéfico ocorre uma baixa produção de $\lg A$, que se liga ao agente e facilita a adesão deste na mucosa intestinal formando um biofilme que protege contra infecção por outros microorganismos e evita a translocação dessa bactéria através da mucosa do hospedeiro (inclusão imunológica). Por outro lado, microorganismos que causam lesão, estimulam a produção de altos níveis de $\lg A$ que inibem o agente e impedem a adesão deste ao hospedeiro (exclusão imunológica). A exclusão/inclusão imunológica previne o movimento de microrganismos através da mucosa pela combinação de aumento da produção de muco e de $\lg A$ (Everret et al., 2004).
Estes mecanismos de competição entre os microorganismos e a interação do agente com o hospedeiro promovem - equilíbrio ou desequilíbrio da microbiota gastrointestinal. $\mathrm{O}$ desequilíbrio é entendido como a predominância de microorganismos patogênicos com conseqüente redução de microorganismos benéficos como Lactobacillus sp., por exemplo. Dessa forma, é importante conhecer e avaliar as alternativas existentes no mercado que possam controlar a microbiota e trazer benefícios a saúde dos frangos de corte, como ácidos orgânicos e óleos essenciais.

\section{Ácidos Orgânicos}

Os ácidos orgânicos são constituintes naturais de plantas e animais. Alguns podem ser formados através da fermentação microbiana no intestino e outros nas rotas metabólicas intermediárias (Lehninger et al., 1993). Como grupo químico os ácidos orgânicos são considerados como sendo qualquer substância de estrutura geral $\mathrm{R}-\mathrm{COOH}$, gerando grupos de compostos relacionados, conhecidos como derivados dos ácidos carboxílicos, como os aminoácidos, ácidos graxos, coenzimas e metabólitos intermediários (Solomon e Fryhle, 2002). Aqueles associados com atividade antimicrobiana são os ácidos graxos de cadeia curta, tanto monocarboxílicos, como fórmico, acético, propiônico e o butírico ou carboxilados com o grupo hidroxila como lático, málico, tartárico e o cítrico. A tabela 2 mostra o nome comum, a designação química, a fórmula e 0 pKa (constante de dissociação) dos ácidos orgânicos comumente usados em frangos de corte. 
Tabela 2- Lista de ácidos orgânicos e suas propriedades.

\begin{tabular}{|c|c|c|}
\hline Ácido & Químic & órmula \\
\hline Fórmico & Ácido fórmico & $\mathrm{HCOOH}$ \\
\hline Acético & Ácido acético & $\mathrm{CH} 3 \mathrm{COOH}$ \\
\hline Propiônico & Ácido 2-propanóico & $\mathrm{CH} 3 \mathrm{CH} 2 \mathrm{COOH}$ \\
\hline Butírico & $\begin{array}{l}\text { Ácido } \\
\text { Ácido }\end{array}$ & $\mathrm{CH} 3 \mathrm{CH} 2 \mathrm{CH}$ \\
\hline Lático & $\begin{array}{l}\text { propanoico } \\
\text { 4- }\end{array}$ & $\begin{array}{l}\mathrm{CH} 3 \mathrm{CH}(\mathrm{OH}) \mathrm{C} \\
\mathrm{CH} 3 \mathrm{CH}: \mathrm{CHCl}\end{array}$ \\
\hline Sórbico & $\begin{array}{l}\text { hexandienóico } \\
\text { Ácido 2- }\end{array}$ & $\mathrm{OOH}$ \\
\hline Fumárico & $\begin{array}{l}\text { butenodióico } \\
\text { Ácido }- \text { hidroxy-4- }\end{array}$ & $\mathrm{COOHCH}: \mathrm{CHCOOH}$ \\
\hline HMB & & $\mathrm{H}) \mathrm{COOH}$ \\
\hline & hidroxybutanedióic & $\mathrm{COOHCH} 2 \mathrm{CH}(\mathrm{OH}) \mathrm{C}$ \\
\hline Málico & Ácido2,3- & $\mathrm{OOH}$ \\
\hline Tartárico & $\begin{array}{l}\text { Dihydroxy- } \\
\text { butanedioic } \\
\text { Ácido 2-hidroxy- } \\
\text { 1,2,3- }\end{array}$ & $\begin{array}{l}\mathrm{COOHCH}(\mathrm{OH}) \mathrm{CH}(\mathrm{O} \\
\mathrm{H}) \mathrm{COOH}\end{array}$ \\
\hline Cítrico & $\begin{array}{l}\text { propanetricarboxilic } \\
0\end{array}$ & $\begin{array}{l}\mathrm{COOHCH} 2 \mathrm{C}(\mathrm{OH})(\mathrm{C} \\
\mathrm{OOH}) \mathrm{CH} 2 \mathrm{COOH}\end{array}$ \\
\hline
\end{tabular}

Fonte: Dibner e Butin (2002) - modificado.

Os ácidos orgânicos agem diretamente como inibidores do crescimento bacteriano (Heres et al., 2004; Bassan et al., 2008) , sendo utilizados na conservação de grãos e alimentos (Silva, 2005; Sterzo et al., 2007) , sanitização do alimento (Byrd et al., 2001) e aditivo promotor de crescimento em dietas animais (Skinner et al., 1991; Vale et al., 2004; Rezende et al., 2008).

O principal mecanismo de ação dos ácidos refere-se à teoria dos ácidos fracos, exercendo atividade antimicrobiana devido a redução do $\mathrm{pH}$ no interior da célula microbiana (Cherrington et al., 1991; Roth, 1998). A forma não dissociada do ácido é lipossolúvel e nessa forma tem capacidade de atravessar de forma passiva a membrana celular. No interior da célula o ácido se dissocia alterando o $\mathrm{pH}$ citoplasmático, afetando $\mathrm{o}$ metabolismo, alterando o gradiente de prótons e a carga com o exterior, interfere no sistema de transporte de aminoácidos e fosfatos além disso enzimas são inativadas (Russel, 1992). Outra consequência é o aumento da pressão osmótica celular, que desencadeia mecanismos de compensação de carga elétrica aumentando os níveis de sódio, potássio ou glutamato aumentando a força iônica intracelular, provocando um aumento da pressão mecânica sobre a parede do microorganismo, o que faz com que essa se rompa (Russel, 1992).

Recentemente Stratford et al. (2009) contesta que essa teoria seja aplicada a todos os ácidos orgânicos. Em seus estudos os autores discutem a teoria dos ácidos fracos, onde demonstram que nem todos os ácidos necessitam reduzir o $\mathrm{pH}$ no citoplasma para exercer sua atividade antimicrobiana. Por exemplo, no caso do ácido sórbico, observa-se que concentrações inibitórias deste ácido não reduzem $\mathrm{o} \mathrm{pH}$ citoplasmático $\mathrm{e}$ acredita-se que a membrana citoplasmática seja o primeiro sítio de ação deste ácido. A lesão da membrana, a perda da sua integridade $e$ o aumento a permeabilidade a prótons, levam a morte do microorganismo.

Independente do mecanismo exato de ação dos ácidos orgânicos sobre os microorganismos, para ser uma alternativa viável ao uso de antibióticos como aditivos alimentares, os ácidos orgânicos devem apresentar resultados similares, sem comprometer a saúde animal e sem provocar resistência ou deixar resíduos na carne.

Estudos avaliando o desempenho zootécnico de frangos de corte e o uso de ácidos orgânicos apresentam resultados controversos, provavelmente devido aos diferentes modos de ação, condições ambientais, dose utilizada e parâmetros avaliados. Rezende et al. (2008) avaliaram diferentes níveis de inclusão de ácido acético (0; $0,5 \%$; $1,0 \%, 1,5 \%$ e $2,0 \%$ ) em rações de frango experimentalmente contaminadas com Salmonella sp. e 
observaram que a inclusão do ácido orgânico em todos os níveis avaliados melhorou os parâmetros zootécnicos dos animais (ganho de peso e conversão alimentar) porém, no que se refere ao controle microbiológico, o uso do ácido orgânico não foi satisfatório. No entanto, Maiorka et al. (2004) não observaram diferenças significativas no ganho de peso de frangos de corte na fase de 1 a 21 dias de idade com a inclusão de uma mistura de ácidos fumárico $(0,5 \%)$, lático $(5,13 \%)$, cítrico $(5,4 \%)$ e ascórbico $(1,2 \%)$ na dieta, isto pode ter ocorrido pois em ambientes com menor status sanitário ou com algum tipo de desafio o ácido orgânico pode expressar melhor o seu potencial. Vale et al. (2004) utilizando uma mistura de ácido fórmico e propiônico verificaram que a inclusão de até $1 \%$ na ração não altera o desempenho dos animais. Porém a inclusão de $2 \%$ desta mistura promoveu menor consumo de ração e de ganho de peso na fase inicial (1-21 dias). Skinner et al. (1991), observaram que a inclusão de 0,125\% de ácido fumárico na ração melhorou o ganho de peso de frangos aos 49 dias de idade e o consumo de ração foi maior quando incluiu-se 0,125 e $0,5 \%$ de ácido na dieta. A diferença entre as metodologias dos estudos podem justificar os resultados, pois além de se tratarem de diferentes ácidos orgânicos e inclusões, provavelmente em condições de maior desafio sanitário, os ácidos orgânicos expressam melhor o seu potencial. Nos trabalhos avaliados, geralmente em ambientes com boas condições sanitárias o uso dos ácidos orgânicos não apresentou melhoras significativas no desempenho zootécnico sugerindo que seu uso seja indicado principalmente em granjas com altos desafios sanitários.

A presença de ácidos graxos de cadeia curta no intestino pode aumentar a produção de muco, seja pela estimulação dos receptores químicos conectados aos nervos colinérgicos ou por efeito direto nas células caliciformes (Vattay et a.l, 1988). A maior secreção de muco promove a proteção da parede intestinal contra agentes agressores da dieta, ou mesmo bactérias patogênicas, reduzindo sua presença no intestino. Os ácidos podem estimular a proliferação de enterócitos, sugerindo melhora na capacidade de absorver os nutrientes (Sakata, 1987).

A adição de ácido butírico na dieta auxilia na manutenção da estrutura das vilosidades (Leeson et a.l, 2005), além disso, ácidos como propiônico e butírico podem ter ação trófica sobre a estrutura e 0 desenvolvimento intestinal, aumentando o tamanho dos vilos, a massa intestinal e a área de superfície de absorção (Sakata,1987). Porém alguns autores não obtiveram resultados conclusivos com relação a altura de vilosidades e profundidade de criptas de frangos tratados com ácido lático e ácido butírico na dieta (Salazar et al, 2008), assim como Chaveerah et al (2004), também não observaram diferenças significativas na estrutura intestinal em frangos desafiados com Campylobacter e tratados com ácidos orgânicos na água.

Diversos estudos relatam o uso de ácidos orgânicos como controladores da microbiota de frangos de corte. Alp et al. (1999) avaliaram a suplementação de dietas de frangos com $0,1 \mathrm{~g} / \mathrm{kg}$ de bacitracina de zinco e/ou uma mistura de ácidos orgânicos (lático, fumárico, propiônico, cítrico e fórmico - 3kg/ton) e observaram que houve redução na contagem de Enterobactérias em conteúdo intestinal de íleo dos animais tratados somente com ácidos, do que somente com bacitracina de zinco, porém quando houve a associação destes dois produtos obteve-se a menor contagem bacteriana, aos 42 dias de vida dos animais. Sterzo et al. (2007), utilizando 1,5 e 3,0 kg/ton de mistura comercial de ácidos orgânicos na ração 
de frangos observaram redução significativa na contagem de Salmonella sp. em conteúdo cecal, quando comparado ao grupo controle (sem o aditivo) aos 3,5 e 7 dias após a inoculação. Bassan et al. (2008) observaram que a adição de uma mistura de ácido fórmico e propiônico (4 $\mathrm{kg} / \mathrm{ton}$ ) na dieta de frangos reduz a colonização por Salmonella sp. na tonsila cecal a partir do 180 dia após a inoculação, sendo que a bactéria foi eliminada a partir do 280 dia pós inoculação. Silva (2005) concluiu que os tratamentos com ácidos orgânicos na concentração de $30 \mathrm{~kg} / \mathrm{ton}$ mostraram-se eficazes na inibição do crescimento da Salmonella sp. em rações avícolas, após $24 \mathrm{~h}, 48 \mathrm{~h}$ e sete dias de contato do produto com a ração contaminada. Heres et al. (2004), avaliaram a eficácia uma mistura de ácidos orgânicos (5,7\% de ácido lático e 0,7\% de ácido acético) contra Salmonella sp. e Campylobacter $\mathrm{sp}$. O teste in vitro mostrou que estes ácidos são eficientes em eliminar estas bactérias, porém quando testados na dieta de frangos os autores observaram que o ácido orgânico foi mais eficiente em eliminar o Campylobacter sp. do que a Salmonella sp.

O uso de ácidos orgânicos na água antes do abate dos animais pode ser uma alternativa viável para redução de microorganismos patogênicos, como sugere Byrd et al. (2001) que observou redução na incidência de Salmonella sp. e Campylobacter sp. em papo e em carcaças de frangos após o uso de uma solução de $0,5 \%$ de ácido acético, lático e fórmico 8 horas antes do abate. Avila et al. (2003) observaram redução na contagem de Salmonella sp. em papo de frangos com a adição de mistura comercial de ácidos na água 24 horas antes do abate. Observou-se redução na contagem de Campylobacter sp. e de Enterobactérias em papo e ceco de frangos inoculados com Campylobacter sp. e tratados com uma mistura de ácidos orgânicos na água por 10 dias (Chaveerach et al., 2004).

Animais tratados com ácidos orgânicos apresentam maior número de Lactobacillus e de bactérias totais em comparação com o grupo controle ou tratados com antibióticos. Os autores concluíram que ácidos orgânicos são uma alternativa viável ao uso de antibióticos por promoverem aumento nas bactérias benéficas do trato gastrointestinal e dessa forma reduzirem as patogênicas (Nava et al., 2009).

\section{Óleos Essenciais}

Óleos essenciais constituem-se em complexas misturas de substâncias voláteis, geralmente lipofílicas (Simões e Spitzer, 1999), cujos componentes incluem hidrocarbonetos terpênicos, álcoois simples, aldeídos, cetonas, fenóis, ésteres, ácidos orgânicos fixos, etc, em diferentes concentrações, nos quais, um composto farmacologicamente ativo é majoritário. A substância que constitui o princípio ativo de um óleo essencial pode ser encontrada em diversas plantas, às vezes em concentrações diferentes. $O$ timol pode ser encontrado no óleo essencial de tomilho (41\%) e no óleo essencial de orégano (10\%), porém só pode ser considerado princípio ativo do tomilho, sendo que o princípio ativo do orégano é o carvacrol, presente em $60 \%$ do óleo (Kamel, 2000).

A literatura cita diversos usos dos óleos essenciais e fitoterápicos, seja como melhoradores do desempenho (Giannenas et al., 2003; Lee et al., 2004), melhoradores das funções digestivas (Lee et al., 2003) e moduladores da microbiota intestinal (Mitsch et al., 2004; Mountzouris et al., 2011).

O mecanismo de ação dos óleos essenciais podem variar de acordo com a substância avaliada, por exemplo, o carvacrol e o timol, componentes dos 
óleos essenciais de orégano e tomilho, tornam a membrana celular permeável, desintegram a membrana externa de bactérias gram-negativas, liberando lipopolissacarídeos e aumentando a permeabilidade da membrana plasmática de ATP (Ultee et al., 2002). O componente hidrofóbico do carvacrol interage com a membrana bacteriana alterando a permeabilidade a cátions como $\mathrm{H}_{+}$e $\mathrm{K}+$. A dissipação de gradientes de íons leva à insuficiência dos processos vitais na célula e, finalmente, à morte celular. (Ultee et al., 2002).

A alteração da permeabilidade da membrana das paredes celulares das bactérias se deve ao caráter lipofílico dos óleos essenciais que se acumulam nas membranas. As bactérias gramnegativas possuem uma membrana externa que contém lipopolissacarídeos, formando uma superfície hidrofílica. Este caráter hidrofílico cria uma barreira à permeabilidade das substâncias hidrofóbicas como óleos essenciais, explicando a resistência de bactérias gram-negativas a esses aditivos (Dorman e Deans, 2000).

Estudos in vitro indicam forte atividade bactericida e fungicida do carvacrol contra as principias bactérias e fungos causadores de infecções como E. coli, Enterobacter spp., Bacillus spp., Salmonella spp., Candida spp., Fusarium spp., Aspergillus spp., Rhizopus spp. e Penicillium spp. (Sivropoulou et al., 1996; Sahin et al., 2004) Escherichia coli O157:H7 e Salmonella enterica sorovar Typhimurium (Helander et al., 1998), Staphilococcus aureos e Pseudomonas aeroginosa (Lambert et al., 2001). Santurio et al. (2007) estudaram a atividade in vitro do carvacrol frente 60 sorovares de Salmonella entérica e o óleo essencial de orégano evidenciou forte atividade bacteriana contra este gênero, principalmente os sorovares
Senftenberg, Tennessee, Pullorum e Rissen.

Pesquisas realizadas com frangos de corte parecem confirmar as respostas obtidas in vitro. Mitsch et al. (2004) observaram que houve redução na contagem de Clostridium perfringens em jejuno, ceco, cloaca e fezes de frangos quando foram incluídos na ração 100 ppm de uma mistura de óleos essenciais a base de carvacrol, timol, cinamaldeído, eugenol e capsaícina, durante 14 dias. Mountzouris et al., (2011) observaram que o uso de um fitoterápico composto por orégano, anis e citrus levou a modulação da microbiota de frangos com redução de coliformes e aumento de bifidobactérias e lactobacilos no ceco. Houve redução na contagem de Clostridium perfringens em ceco de frangos quando foi utilizado uma mistura de óleos essenciais de orégano, alecrim, canela e extrato de pimenta (100 ppm) durante 14 dias na ração. No grupo tratado com o promotor de crescimento avilamicina (10 ppm) não foi detectada presença desta bactéria (Bona, 2010) Ainda neste trabalho observou-se, que esta mistura de óleos essenciais também possui atividade no controle de Salmonella sp.. Houve redução na contagem de Salmonella sp. no grupo tratado com avilamicina $24 \mathrm{~h}$ pós inoculação e no grupo tratado com a mistura de óleos essenciais esta redução só foi observada $72 \mathrm{~h}$ pós inoculação (Bona, 2010). Este trabalho demonstra que os óleos essenciais podem ser alternativas viáveis aos antibióticos no controle da enterite necrótica e da salmonelose em frangos. Enquanto 0 promotor de crescimento apresenta efeito imediato no controle da microbiota os óleos essenciais necessitam de maior tempo para exibirem o seu potencial.

Silva et al (2009) avaliaram frangos alimentados com óleo essencial de orégano $(0,5 \mathrm{~g} / \mathrm{kg}$ ou $1 \mathrm{~g} / \mathrm{kg}$ de ração) ou com anticoccidiano e desafiados com 
Eimeria tenella e observaram redução na eliminação de oocistos nos animais tratados tanto com o óleo essencial e com 0 anticoccidiano. Observou-se também maior espessura da lâmina própria de ceco de animais que não apresentavam aditivos na ração, quando comparado aos grupos tratados com orégano e anticoccidiano, 6 e 22 dias após inoculção com Eimeria tenella, indicando que o orégano pode reduzir a ação do patógeno no ceco, contribuindo com a manutenção da integridade intestinal.

Óleos essenciais podem atuar como melhoradores de desempenho zootécnico de frangos de corte. Frangos alimentados com uma combinação de 300 ppm extratos vegetais a base de orégano, canela e pimenta apresentaram maior ganho de peso e melhor conversão alimentar que os animais do tratamento controle, pois de acordo com os autores, a suplementação com extratos vegetais aumentou a digestibilidade dos nutrientes e favoreceu o equilíbrio da microbiota, diminuindo o potencial de adesão de patógenos ao epitélio intestinal (Jamroz e Kamel, 2002). Uma mistura comercial de óleos essenciais na ração de frangos desafiados com Eimeria tenella, melhorou 0 desempenho zootécnico (ganho de peso, consumo de ração e conversão alimentar), porém não foram observadas redução nas lesões em ceco dos animais (Christaki et al., 2004).Por outro lado, Fukaiama et al. (2005), não observaram diferenças no desempenho, rendimento de carcaça e na morfometria intestinal de frangos alimentados com diferentes concentrações de extrato de orégano $(0,025 \% ; 0,05 \% ; 0,075 \%$ e $0,1 \%$ ) e 25 ppm de bacitracina de zinco, assim como Jamroz et al., (2006) não observaram influencia dos extratos de carvacrol, cinamaldeído e capsaicina no desempenho zootécnico de frangos de corte, porém observaram aumento na produção de muco em proventrículo e jejuno destes animais. O uso de uma mistura comercial de orégano, cinamaldeído, timol e capsaicina também não mostraram benefícios no desempenho zootécnico de frangos de corte (Zhang et al., 2005).

\section{CONCLUSÃO}

A proliferação de bactérias no trato gastrointestinal, principalmente patogênicas, deve ser minimizada principalmente por meio de práticas adequadas de manejo e nutrição, devendo os ácidos orgânicos e óleos essenciais ser utilizados como alternativas ao controle de microorganismos patogênicos e promover melhorias na saúde intestinal, bem como no desempenho das aves. Os resultados da literatura indicam que os diferentes efeitos obtidos com o uso dos ácidos orgânicos e óleos essenciais dependem da dose e do tipo de ácido ou óleo utilizado. Porém devido aos diferentes mecanismos de ação os óleos essenciais e ácidos orgânicos necessitam de maior tempo para demonstrar seus efeitos tanto como melhoradores de desempenho ou como controladores da microbiota intestinal. Mas fica evidente que o uso destes aditivos na produção de frangos pode trazer benefícios, seja no desempenho zootécnico dos animais, ou no controle da microbiota intestinal, reduzindo a contaminação por bactérias patogênicas em toda a cadeia de produção, demonstrando viabilidade no seu uso.

\section{REFERÊNCIAS}

ALP, M.; KOCABAGLI, N.; KAHRAMAN,R.; BOSTAN,K. Effects of Dietary supplementation with Organic Acids and Zinc Bacitracin on lleal Microflora, $\mathrm{pH}$ and Performance in Broilers. Turkish Journal of Veterinary and Animal Sciences, n. 23, p.451-455, 1999. 
AMIT-ROMACH, E.; SKLAN,D.; UNI, Z. Microflora Ecology of the Chicken Intestine Using 16S Ribosomal DNA Primers. Poultry Science, v. 83, p.1093-1098, 2004.

AVILA, L.A.F.; NASCIMENTO, V.P.; CANAL, C.W.; SALLE C.T.P.; MORAES, H.L. S. Effect of Acidified Drinking Water on the Recovery of Salmonella enteritidis from Broiler Crops. Brazilian Journal of Poultry Science, v. 5, n.3, p. $183-188,2003$.

BASSANI, J.D.; FLÔRES, M.L.; ANTONIAZZI, T.; BIANCHI, E.; KUTTEL, J.;TRINDADE, M.M. Controle da infecção por Salmonella enteritidis em frangos de corte com ácidos orgânicos e mananoligossacarídeo. Ciência Rural, v.38, n.7, 2008.

BONA, T.D.M.M. Avaliação de Óleo Essencial de Orégano, Alecrim, Canela e Extrato de Pimenta no Controle de Salmonella, Eimeria e Clostridium em frangos de corte. Dissertação (Mestrado em Ciências Veterinárias), Universidade Federal do Paraná, Curitiba, Paraná, 50p, 2010.

BYRD, J.A.; HARGIS,B.M.; CALDWELL,D.J.; BAILEY,R.H.; HERRON,K.L.; MCREYNOLDS,J.L.; BREWER, R.L.; ANDERSON,R.C.; $\quad$ BISCHOFF,K.M.; CALLAWAY,T.R.; KUBENA, L.F. Effect of Lactic Acid Administration in the Drinking Water During Preslaughter Feed Withdrawal on Salmonella and Campylobacter Contamination of Broilers. Poultry Science, n. 80, p.278-283, 2001.

CASEWELL, M.; FRIIS, C.; GRANELL, E.M.; MCMULLIN, P.; PHILLIPS, I. The European ban on growth-promoting antibiotics and its consequences for human and animal health. Journal of Antimicrobial Chemotherapy, n. 52, p.159-161, 2003.

CHAVEERACH, P.; KEUZENKAMP,D.A.; LIPMAN,L.J.A.; VAN KNAPEN,F. Effect of Organic Acids in Drinking Water for Young Broilers on Campylobacter Infection, Volatile Fatty Acid Production, Gut Microflora and Histological Cell Changes, Poultry Science, n. 83, p.330-334, 2004.
CHERRINGTON, C.A.; HINTON, M.; CHOPRA, I. Organic Acids: Chemistry antibacterial activity and practical application. Advances in Microbiological Phisiology, v. 32, p.87-108, 1991.

CHRISTAKI, E.; FLOROU-PANERI,P.; GIANNENAS,I.; PAPAZAHARIADOU, M.; BOTSOGLOU, N.A.; SPAIS, A.B. Effect of a mixture of herbal extracts on broiler chickens infected with Eimeria tenella. Animal Research, n. 53, p.137-144, 2004.

DIBNER, J.J.; RICHARDS, J.D. Antibiotic growth promoters in agriculture: History and mode of action. Poultry Science, n.84, p.634-643, 2005.

DIBNER, J.J.; BUTTIN,P. Use of organic acids.s a model to study the impact of gut microflora on nutrition and metabolism. Journal of Applied and Poultry Research, n. 11, p. 453-463, 2002.

DORMAN, H.J.D.; DEANS, S.G. Antimicrobial agents from plants: antibacterial activity of plant volatile oils. Journal of applied Microbiology, v. 88, p. 308-316, 2000.

EVERETT, M. L.; PALESTRANT,D.; MILLER,S.E.; BOLLINGER,R.R.; PARKER,W. Immune exclusion and immune inclusion: A new mode of host-bacterial interactions in the gut. Clinical and Applied Immunologoly Reviews, n.4, p.321-332, 2004.

GIANNENAS, I; FLOROU PANERI, P.; PAPAZAHARIADOU, M.; CHRISTAKI, E.; BOTSOGLOU, N.A.; SPAIS, A.B. Effect of dietary supplementation with oregano essential oil on performance of broilers after experimental infection with Eimeria tenella. Archives of Animal Nutrition, n. 57, p. 99-106, 2003.

HART, A.; STAAG, L.A.J.; FRAME, M.; GRAFNNER, H.; GLISE, H.; FALK, P.; KAMM, M.A. The role of the gut flora in health and disease and its modification as therapy. Alimentary Pharmacology Therapeutics, p. 1383-1393, 2002.

HELANDER, I.M. Characterization of the action of selected essential oil components on Gram 
negative bacteria. Journal of Agricultural and Food Chemistry, n. 46, p. 3590-3595. 1998.

HERES,L.; ENGEL,B.; URLINGS, H.A.P.; WAGENAAR, J.A.; VAN KNAPEN, F. Effect of acidified feed on susceptibility of broiler chickens to intestinal infection by Campylobacter and Salmonella. Veterinary Microbiology, n. 99, 259-267, 2004.

HINTON, A. JR.; BUHR, R. J.; INGRAM, K. D. Reduction of Salmonella in the crop of broiler chickens subjected to feed withdrawal. Poultry Science, n. 79, p.1566-1570, 2000.

JAMROZ, D.; KAMEL, C. Plant extracts enhance broiler performance. Journal of Animal Science. v.80, p. 41, 2002.

JAMROZ, D.; WERTELECKI, J.; HOUSZKA, M.; KAMEL, C. Influence of diet type on the inclusion of plant origin active substances on morphological and histochemical characteristics of the stomach and jejunum walls in chicken. Journal of Animal Physiology and Animal Nutrition, n. 90, p.255-268, 2006.

JANSSEN, A. M.; CHIN, N. L. J.; SCHEFFER, J. J. C.; BAERHEIM SVENDSEN, A. Screening for antimicrobial activity of some essential oils by the agar overlay technique. Statistics and correlations. Pharmaceutisch Weekblad Scientific Edition. n.8, p.289-292, 1986.

JEAUROUND, E.; SCHUMANN, B.; CLUNIES, $M$. Supplementation of diets with herbal extracts enhances growth performance in newly-weaned piglets. Journal of Animal Science, v.80, p.394, 2002.

JIANGRANG L.; IDRIS,U.; MAURER,J.J.; HARMON,B.; LEE, M.D.; HOFACRE, C. Diversity and Succession of the Intestinal Bacterial Community of the Maturing Broiler Chicken. Applied and environmental microbiology, p. 6816-6824, 2003.

KAMEL, C. A novel book at a classic approach of plant extracts. Feed mix - The International Journal of Feed Nutrition and Technology Special: Alternatives of Antibiotics, p.19-21, 2000.
KIMURA, N.; MIMURA, F.; NISHIDA, S.; KOBAYASHI, A. Studies on the relationship between intestinal flora and cecal coccidiosis in chicken. Poultry Science, n. 55, p.1375-1383, 1976.

KNARREBORG, A.; SIMON, M.A.; ENGBERG, M.R.; JENSEN,B.B.; TANNOCK, G.W. Effects of dietary fat source and subtherapeutic levels ofantibiotic on the bacterial community in the ileum of Broiler Chickens at Various Ages. Applied and Environmental Microbiology, v. 68, n.12, p. 5918-5924, 2002.

LAMBERT, R.J.W.; SKANDAMIS, P.; COOTE, P.J.; NYCHAS, J. A study of the minimum inhibitory concentration and mode of action of oregano essential oil, thymol and carvacrol. Journal of Applied Microbiology, n.91, p.453462, 2001.

LEE, K.W.; EVERTS, H.; BEYNEN, A.C. Essential oils in broiler nutrition. International Journal of Poultry Science, n. 3, p. 738-752, 2004.

LEE, K.W.; KAPPERT, H.J.; FREHNER, M.; LOSA, R.; BEYNEN, A.C. Effects of dietary essential oil components on growth performance, digestive enzymes and lipid metabolism in female broiler chickens. British Poultry Science, n. 44, p. 450-457, 2003.

LEESON, $\quad$ S.; $\quad$ NAMKUNG, H.; ANTONGIOVANNI,M.; LEE, E.H. Effect of butyric acid on the performance and carcass yield of broiler chickens. Poultry Science, v. 84, p. 1418-1422, 2005.

LEHNINGER, A.L.; NELSON, D.A.; COX,M.M. Principles of Biochemistry. New York. Worth Publishers, 576p.; 1993.

MAIORKA, A.; SANTIN, E.; BORGES, S. A.; OPALINSKI, M.; SILVA, A. V. F. Emprego de uma mistura de ácidos fumárico, lático, cítrico e ascórbico em dietas iniciais de frangos de corte. Archives of Veterinary Science, v. 9, n. 1, p. 31-37, 2004.

MCLEAN,J.; NEVISON,I.; $\quad$ BERTIN,G.; ACAMOVIC,T. Dietary supplementation of 
xylanase (Allzyme PT) in wheat-based diets, on broiler performance from day-old to 42 days of age. International Poultry Scientific Forum Abstracts, Georgia World Congress Center, Atlanta, Georgia, USA, p. 41, 2004.

MENTEN, J.F.M. Aditivos alternativos na produção de aves: probióticos e prebióticos. In: REUNIÃO ANUAL DA SOCIEDADE BRASILEIRA DE ZOOTECNIA, 2001, Piracicaba. Anais... Piracicaba: ESALQ/USP, p.141-157, 2001.

MILES, R.O. Manipulation of the microflora of Ihe gastrointestinal tract: natural ways to prevem colonization by pathogens. 111: Altech Biotechnology in the Feed and Oustry, Proceedings, p.133-50,1993.

MILTENBURG, G. Extratos herbais como substitutos de antimicrobianos na alimentação animal. In: SIMPÓSIO SOBRE ADITIVOS ALTERNATIVOS NA NUTRIÇÃO ANIMAL, 2000, Campinas. Anais... Campinas: CBNA, p.87-100, 2000.

MITSCH, P.; ZITTERL-EGLSEER,K.; KOHLER,B.; GABLER, C.; LOSA,R.; ZIMPERNIK I. The effect of two different blends of essential oil components on the proliferation of Clostridium perfringens in the intestines of broiler chickens. Poultry Science, n. 87, p. 669675, 2004.

MOUNTZOURIS, K.C.; V. PARASKEVAS, V.; TSIRTSIKOS, P.; PALAMIDI, I.; SCHATZMAYR, G.; FEGEROS, K. Assessment of a phytogenic feed additive effect on broiler growth performance, nutrient digestibility and caecal microflora composition. Animal Feed and ScienceTechnology, 2011, (in press).

NAVA, M. G.; ATTENE-RAMOS, M.S.; GASKINS, H.R.; RICHARDS, J.D. Molecular analysis of microbial community structure in the chicken ileum following organic acid supplementation. Veterinary Microbiology, n.137, p.345-353, 2009.

NURMI, E.; RANTALA, M. New aspects of Salmonella infection in broiler production. Nature, n. 241, p. 210-211, 1973.
REZENDE, C.S.M.; MESQUITA, A.J.; ANDRADE, M.A.; STRINGHINI, J.H.; CHAVES, L.S.; MINAFRA, C.S.; LAGE, M.E. Ácido acético em rações de frangos de corte experimentalmente contaminadas com Salmonella enteritidis e Salmonella typhimurium. Revista Brasileira de Saúde e Produção Animal, v.9, n.3, p. 516-528, 2008.

ROTH, F. X.; KIRCHGESSNER, M. Organic acids as feed additives for young pigs: nutritional and gastrointestinal effects. Journal of Animal and Feed Science, n. 8, p. 25-33, 1998.

RUSSEL, J.B. Another Explanation for the toxicity of fermentation acids at low $\mathrm{pH}$ : anion accumulation versus uncoupling. Journal of Applied Bacteriology, v.73, p.363-370, 1992.

SAHIN, F.; GULLUCE, M.; DAFERERA, D.; SOKMEN, M.; POLISSIOU, M.; AGAR, G.; OZER, H. Biological activities of the essential oils and methanol extract of Origanum vulgare ssp. vulgare in the Eastern Anatolia region of Turkey. Food Control, n.15, p.549-557, 2004.

SAKATA, T. Stimulatory effect of short-chain fatty acids on epithelial cell proliferation in the rat intestine: a possible explanation for trophic effects of fermentable fiber, gut mibrobes and luminal trophic factor. British Journal of Nutrition, v. 58, n. 95, p. 95-103, 1987.

SALAZAR, P.C.R.; ALBUQUERQUE, R.; TAKEARA, P. TRINDADE NETO, M.A.; ARAÚJO, L.F. Efeito dos ácidos lático e butírico, isolados e associados, sobre o desempenho e morfometria intestinal em frangos de corte. Brazilian Journal of Veterinary Reserch of Animal Science, v. 45, n. 6, p. 463-471, 2008.

SANTOS, F.B.O.; SHELDON, B.W.; SANTOS JR, A.A.; FERKET, P.R.; LEE, M.D.; PETROSO, A.; SMITH, D. Determination of Ileum Microbial Diversity of Broilers Fed Triticale- or Corn-Based Diets and Colonized by Salmonella. Journal Applied of Poultry Research, v. 16, p. 563573, 2007.

SANTURIO, J.M.; SANTURIO, D.F.; FRANCHIN, P.R.; POZZATTI, P.; ALVES, S.H.; MORAES,C. Atividade antimicrobiana dos óleos essenciais de orégano, tomilho e canela, frente 
a sorovares de Salmonella enterica de origem avícola. Ciência Rural, v. 37, n.3, p. 803-808, 2007.

SILVA, L.C.C. Avaliação de um ácido orgânico como agente inibidor do crescimento de Salmonella sp em rações de aves. Brazilian Journal of Poultry Science, Supl.7, p.219, 2005.

SILVA, M.A.; PESSOTTI, B.M.S.; ZANINI, S.F.; COLNAGO, G.L.C.; RODRIGUES, M.R.A.; NUNES, L.C.; ZANINI, M.S.; MARTINS, I.V.F. Intestinal mucosa structure of broiler chickens infected experimentally with Eimeria tenella and treated with essential oil of oregano. Ciência Rural, v.39, n.5, p.1471-1477, 2009.

SIMÕES, C.M.O.; SPITZER, V. Óleos voláteis. In: SIMÕES, C.M.O. et al. Farmacognosia: da planta ao medicamento. Porto Alegre: UFRGS, Cap.18, p.387-416, 1999.

SIVROPOULOU, A.; PAPANIKOLAOU, E.; NIKOLAOU, C.; KOKKINI, S.; LANARAS, T. ARSENAKIS, M. Antimicrobial and Cytotoxic Activities of Origanum Essential Oils. Journal of Agriculture and Food Chemistry, n. 44, p.1202-1205, 1996.

SKINNER, J.T.; IZAT, A.L.; WALDROUP, P.W. Research note: fumaric acid enhances performance of broiler chickens. Poultry Science, n. 70, v.6, p.1444-1447, 1991(abstract).

SOLOMON, G.; FRYHLE, C. Química Orgânica, 7 ed.. Rio de Janeiro: LTC Livros Técnicos e Científicos, v.1 e 2, 2002.

STERZO, E.V.; PAIVA, J.B.; MESQUITA, A.L.; FREITAS NETO, O.C.; BERCHIERI, Jr A. Organic acids and/or compound with defined microorganisms to control Salmonella enterica serovar Enteritidis experimental infection in chickens. Brazilian Journal of Poultry Science, v. 9, n.1 p. $69-73,2007$.

STRATFORD, M.; PLUMRIDGE, A.; NEBEVON-CARON, G.; ARCHER, D.B. Inhibition of spoilage mould conidia by acetic acid and sorbic acid involves different modes of action, requiring modification of the classical weak-acid theory. International Journal of Food Microbiology, v. 136, p. 37-43, 2009.

TANNOCK, O.W. Studies of the intestinal microflora: a prerequisite for the development of probiotics. International Dairy Journal, v.8, p.527-33, 1998.

TELLEZ, G.; HIGGINS, S.E.; DONOGHUE, A.M.; HARGIS, B.M. Digestive Physiology and the Role of Microorganisms. Journal Applied of Poultry Research, n. 15, p.136-144, 2006.

TOROK, V.A.; HUGHES, R.J.; OPHEL-KELLER, K.; ALI, M.; MACALPINE, R. Influence of different litter materials on cecal microbiota colonization in broiler chickens. Poultry Science, n. 88, p. 2474-2481, 2009.

ULTEE, A., BENNINK, M.H.J.; MOEZELAAR, R. The phenolic hydroxyl group of carvacrol is essential for action against the food-borne pathogen Bacillus cereus. Applied and Environmental Microbiology, n. 68, v.4, p. 1561-1568, 2002.

VALE, M.M.; MENTEN, J.F.M.; MORAIS, S.C.D.; BRAINER, M.M.A. Mixture of formic and propionic acid as additives in broilers feeds. Scientia Agricola, v. 61, n. 4, p.371-375, 2004.

VAN DER WIELEN, P.W.; BIESTERVELD, S.; NOTERMANS, S.; HOFSTRA, H.; URLINGS, B.A.P.; VAN KNAPEN, F. Role of volatile fatty acids in development of the cecal microflora in broiler chickens during growth. Applied and Environmental Microbiology ,n. 66, p. 25362540, 2000.

VATTAY, P.; FEIL, W.; KLIMESCH, S.; WENZI, E.; STARLINGER, M.; SCHIESSERL, R. Acid stimulated alkaline secretion in the rabbit duodenum is passive and correlates with mucosal damage. Gut, v. 29, p. 284-290, 1988.

WHO - WORLD HEALTH ORGANIZATION. Global principles for the containment of antimicrobial resistance in animals intended for food. in document WHO/CDS/ CSR/APH/2000. WHO, Geneva, Switzerland, p.1-23, 2000. 
WHO - WORLD HEALTH ORGANIZATION. The medical impact of the use of antimicrobials in food animals: Report of a WHO meeting, Berlin, Germany. p.1-39, 1997.

ZHANG, K.Y.; YAN, F.; KEEN, C.A.; WALDROUP, P.W. Evaluation of Microencapsulated Essential Oils and Organic Acids in Diets for Broiler Chickens. International Journal of Poultry Science, n.4, v.9, p. 612619, 2005.

ZHU, X.Y., ZHONG, T., PANDYA, Y., JOERGER, R., 16S rRNA-based analysis of microbiota from the cecum of broiler chickens. Applied and Environmental Microbiology, n. 68, 124-137, 2002. 